\title{
El Llibre dels secrets d'agricultura, casa rústica i pastoril (1617) de Miquel Agustí: un llibre no del tot obert
}

\author{
Xavier Luna-Batlle \\ Grup de recerca Scripta i projecció dialectal (Universitat de Barcelona)
}

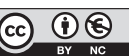

Enviat: novembre de 2013

Acceptat: desembre de 2013

\begin{abstract}
Resum
El Llibre dels secrets d'agricultura, casa rústica i pastoril de Miquel Agustí és l'obra de temàtica agrícola i de la vida rural més important impresa en català. Aparegué el 1617 a Barcelona, i hi hagué nombroses edicions en castellà. Desperta un notable interès des de diferents aspectes lingüístics, culturals i històrics. Aquí es mostren aquestes línies d'interès, els estudis que s'han esbossat fins ara i aquells espais de recerca que caldrà anar omplint, en properes investigacions, per arribar a tenir una idea de conjunt de la transcendència i el significat del llibre en la seva època $i$ en els períodes posteriors.
\end{abstract}

Paraules clau: Catalunya; segle xvII; agricultura; cultura rural; impremta; text; llengua catalana

Resumen. El Llibre dels secrets d'agricultura, casa rústica i pastoril (1617) de Miquel Agustí: un libro no del todo abierto

El Llibre dels secrets d'agricultura, casa rústica i pastoril de Miquel Agustí es la obra de temática agrícola y de la vida rural más importante impresa en catalán. Apareció en 1617 en Barcelona, edición a la que siguieron otras ediciones en castellano. Despierta un notable interés desde diferentes aspectos lingüísticos, culturales e históricos. Aquí se muestran estas líneas de interés, los estudios que se han esbozado hasta ahora y las nuevas investigaciones que deberían encauzarse en el futuro para que podamos formarnos una idea de conjunto de la transcendencia y el significado del libro en su época y en los períodos posteriores.

Palabras clave: Cataluña; siglo xvII; agricultura; cultura rural; inprenta; texto; lengua catalana

Abstract. The Llibre dels secrets d'agricultura, casa rústica i pastoril (1617) of Miquel Agustí: A not entirely open book

Miquel Agustí's Llibre dels secrets d'agricultura, casa rústica i pastoril (The Book of Agricultural, Cottage and Pastoral Secrets) is the most important work on agriculture and rural life ever printed in Catalan. The book, which was first published in 1617 in Barcelona, was followed by numerous editions in Spanish. The work has attracted considerable interest from various linguistic, cultural and historical scholars. This paper examines these lines of interest, the studies that have been undertaken to date, and potential lines of future research to provide further insight into the importance and significance of this work in both its own time and later periods.

Keywords: Catalonia; 17th century; farming; rural life; printing; text; Catalan language 


\section{Sumari}
1. L'autor
6. En la història de la impremta
2. Les fonts
7. En la història de les mentalitats
3. La part original dels Secrets i les ideologies
4. En la història de la llengua
5. En la història sociolingüística

8. Destinataris i recepció
Bibliografia

El llibre de Miquel Agustí (1560-1630) titulat Llibre dels secrets de agricultura, casa rústica y pastoril, que aparegué a Barcelona el 1617, a la casa de l'impressor Esteve Lliberós - al carrer de Sant Domènec del Call, al cor del Barri Gòtic_ — va ser un llibre molt reeditat, però llevat de la primera edició totes les altres, una vintena, van aparèixer en castellà. El professor Amadeu-J. Soberanas (1988) va fer el seguiment i la descripció de les edicions, i la segona, traduïda pel mateix Miquel Agustí, és impresa a Perpinyà el 1626, en castellà, com totes les que seguiran. La tercera és feta a Saragossa, i després n'hi d'estampades a Madrid i, la majoria, a Barcelona, fins al 1781. La primera edició facsimilar la devem a l'editorial Alta Fulla (1988) i la segona, molt més recent, a Propostes Culturals Andana de Vilafranca del Penedès (2007), totes dues amb estudis introductoris.

El text havia estat objecte de comentaris ens els treballs d'història econòmica de Lluís Argemí, i amb la primera edició facsimilar a l'editorial Alta Fulla el 1988 el llibre se situa en un focus d'atenció renovat per als historiadors i els filòlegs. A la recent Història agrària dels Paüsos Catalans, dirigida per Emili Giralt i Raventós, el llibre torna a deixar-se veure en l'àmbit de l'alta divulgació, especialment gràcies al càpitol de Giralt (2008) dedicat al conreu de la vinya en el volum tercer. En l'àmbit de la lingüística és font de moltes referències en els diccionaris històrics (DCVB, DECat) i ocupa un lloc destacat en el manual Panorama de la lexicografia catalana de Germà Colón i Amadeu-J. Soberanas (1985), on llegim que es tracta d'una «enciclopèdia agrícola, que és un monument de la llengua catalana» (Colón \& Soberanas, 1985: 102); i ha estat una referència bàsica en treballs cabdals en el camp de la lingüística històrica, tant en els aspectes gramaticals com lexicals. La nòmina de les monografies en les quals apareix Agustí és llarga. Ací només esmentarem tres treballs que en pouen material: Joseph Gulsoy (1993) per a la història del present de subjuntiu, Germà Colón (1995) per a la història del lèxic, qui confessa haver-lo llegit amb assiduïtat, i Joan Veny (1978) en un estudi sobre els castellanismes antics del rossellonès.

El que s'ha dit de l'obra de Miquel Agustí en aquests moments es presenta com un feix de plecs solts, prou inconnexos entre ells. La impressió és que som en una etapa d'hipòtesis o de simples idees que caldria desplegar. Per exemple: Emili Giralt, un dels estudiosos més interessat en l'obra del Prior, posa en dubte que l'èxit de l'obra durant dos segles s'expliqui amb la simple idea que es venia perquè no n'hi havia cap d'altra, per insinuar tot seguit altres vies explicatives: 
L'historiador haurà de cercar altres raons per explicar la predilecció dues vegades secular per l'obra de Miquel Agustí. Potser la inèrcia del món rural i el conservadurisme cultural poden contribuir a explicar-ho, com també el caràcter de vademècum agropecuari i de farmacopea domèstica que sens dubte tenia el Llibre del Prior. Potser sí, però no és ara el moment d'escatir-ho. (Giralt, 2002: 328)

Provaré de recollir en aquest escrit els aspectes que han merescut i mereixen l'atenció dels estudiosos i que s'haurien de desenvolupar d'una manera més detallada amb l'objectiu d'arribar a comprendre l'obra tant en el seu moment històric com en les repercussions subsegüents.

\section{L'autor}

Fins fa poc de l'autor dels Secrets d'agricultura de 1617 en sabien només el nom i que havia nascut a Banyoles, perquè el mateix llibre ho diu. Joan Fuguet (2010) ha despullat un document de l'orde de l'Hospital relacionat amb Agustí. L'orde tingué casa i església a Perpinyà i és on possiblement escrigué l'obra essent-ne prior. Els priorats hospitalers complien una funció semblant a les parròquies diocesanes, però en lloc de dependre del bisbe depenien del Gran Prior de Catalunya. Quan un priorat quedava vacant es procedia a l'anomenada col-lació, és a dir la tria del nou prior. El 5 de febrer del 1596 és la data del document que recull el procediment d'admissió de Miquel Agustí on es detallen les proves de sang i llinatge necessàries per ingressar a l'orde de l'Hospital. Calia que els quatre avis fossin nobles, que el pretendent fos de naixement legítim i que no tingués sang jueva ni mora. Per conèixer aquestes condicions es convidava a declarar persones que coneixien l'aspirant. Així sabem que el pare «es deia Miquel Puig Agustí i procedia de can Puig de Centenys (llogaret agregat a Esponellà, prop de Banyoles) i la mare es deia Antiga i era de la família Comelles d'Avinyonet de Puigventós. Respecte dels avis, els testimonis no foren tan precisos, però, com en el cas dels pares, digueren que pertanyien als Puig de Centenys i als Comelles d'Avinyonet.» (Fuguet 2010: 291). No consta que la família fos noble, però sembla que això confirma una certa flexibilitat a l'època. El primer priorat que se li assignà fou el de Cotlliure. Joan Fuguet diu que «no sabem quant de temps va romandre mossèn Agustí a Cotlliure, ni si quan deixà aquest priorat va anar directament al de Perpinyà» i que «sembla que morí a Perpinyà l'any 1630» (Fuguet, 2010: 293).

Tot ens porta a pensar que la seva estada al Rosselló, entre Cotlliure i Perpinyà, va ser llarga, cosa que s'adiu amb la idea que el llibre estigui tan impregnat de la llengua d'aquest territori, com és evident consultant el DCVB o el DECat, i tal com s'ha explicitat en les monografies (Prats \& Rossich, 1988; Luna-Batle, 2004, 2007). Cal tenir en compte també que la distància geogràfica i lingüística entre Banyoles i el Rosselló és força petita, i ho era encara menys abans de la separació del Tractat dels Pirineus (1659). El nostre llibre és editat 42 anys abans de la separació del Rosselló, quan per anar de Barcelona a Perpinyà no calia travessar cap frontera estatal.

Aquest tint dialectal contrasta en algun cas amb la llengua de les notes al 
marge, que són abundants al llarg de tot el text. Hi llegim, per exemple, «embriagar-se» mentre que en el text central hi ha «emborràchia» $\mathrm{o}$ «emborrachareu» (f. 104v), entre altres casos (Luna-Batlle, 2004: 40). La impremta de Barcelona deixà alguna petjada en el llibre i les diferències dialectals entre l'escriptor Agustí i l'impressor barceloní, per dir-ho així, hi són presents. No cal dir l'interès que tindria veure un original que no sabem que s'hagi conservat.

\section{Les fonts}

Lluís Argemí ja havia indicat que «la fuente más importante de Agustí fue la obra de Estienne y Liébault [Agriculture et la maison rustique, primera edició de 1564], especialmente en lo que a medicina se refiere, aunque la estructura agraria en Cataluña fuese fundamentalmente distinta de la que Estienne y Liébault o Quesnay, fundador de la fisiocracia, [...] tenían en mente.» (Argemí, 1985: 8-9). I en la presentació a l'edició facsimilar d'Alta Fulla, Argemí formula el tema dient que Agustí «es refereix a l'obra d'Estienne i Liébault gairebé constantment, a més de presentar una similitud formal amb ella» (Argemí, 1988: 8). Emili Giralt (2008: 331, n. 1) remarca que és «una obra utilitzada per historiadors i filòlegs, malgrat ser un plagi i una traducció parcial de l'Agriculture et la maison rustique (1564) de Charles Estienne i Jean Liébaut. Mancats d'una edició crítica, cal servir-se del llibre del Prior amb molta cautela.» Giralt aquí exagera sens dubte en aquesta caracterització de plagi i ell mateix ja havia explicat el sentit del terme en el context de l'estudi de les fonts i l'època:

[...] parlar de plagi resulta anacrònic tractant-se d'una època en què l'apropiació de textos era una pràctica habitual i un mètode no blasmable entre els escriptors. La mateixa candorosa vanitat implícita en la publicació de la «Nòmina» [d'autors de referència] i les citacions que fa al marge de cada pàgina, exclouen tota intenció de plagi, si entenem aquest com l'apropiació d'un text o d'una idea amagant-ne la procedència. El Prior tira al dret a l'hora de traduir, però procliu a un cert exhibicionisme erudit no s'oblida mai de fer constar la font. Això donava una total credibilitat a tot allò que escrivia. (Giralt, 2002: 336)

Es tracta doncs d'una obra que ja diu que beu dels clàssics (Aristòtil, Cató, Columel·la, Galè, Teofrast, Varró i un llarg etcètera, fins a 86) i que s’insereix en la transmissió dels coneixements pràctics relacionats amb les activitats agropecuàries, de medicina casolana, de menescalia, etc. Ser originals, en aquest diguemne gènere particular dels llibres pràctics i especialment quan es parla del món rural, és difícil; i per altra banda no s'hi demana originalitat sinó eficàcia, potser veritat. En tot cas, això sí, es confirma per poc que s'acarin les dues obres, que Agustí va més enllà de la inspiració i el llibre d'Estienne li fa de plantilla de partida (sense que ell mateix ho deixi gaire clar).

Per aquesta raó el mateix Emili Giralt havia iniciat una recerca curosa de les fonts. El doctor Giralt en morir el 2008 deixava aquesta feina per fer, per bé que iniciada amb un valuós treball sobre la identificació dels autors que esmenta 
Agustí (Giralt, 2002), superant de vegades la dificultat de trobar la forma original dels noms dels autors, que es catalanitzen com era costum a l'època: Charles Estienne es converteix en Carles Esteva (personatge que és Carlo Stefano en la traducció de la seva obra agronòmica feta a Venècia el 1591). La llista d'autors que dóna Agustí passa dels vuitanta, amb algun nom repetit i algun altre citats en el text que no apareix a la nòmina del foli prologal IVv (Giralt, 2002: 327).

Maria Antònia Martí Escayol (2008: 295) ens aporta una formulació molt precisa de la qüestió:

A més del coneixement representat com a informació explícita transmesa pels manuscrits, cal tenir en compte la informació implícita i ens referim aquí a la manera de fer ciència i comunicar-la. Quant al primer punt, els manuscrits segueixen la metodologia de recollir i manllevar informació als textos d'autoritats clàssiques i coetànies medievals i, d'aquesta manera, permeten mantenir viva la tradició fins a l'adveniment de l'agricultura moderna. Miquel Agustí segueix emprant aquest mètode i a les autoritats antigues i medievals n'hi afegeix de coetànies modernes, especialment de Charles Estienne i Jean Liébault, autors de L'Agriculture et maison rustique (nota: 1570, l'original és de 1564).

Els autors dels manuscrits [...] afegeixen l'experiència basada en l'observació de la realitat $i$, per tant, es copia i tradueix el text passant-lo pel sedàs personal $i$ adaptant-lo a un entorn natural determinat, afegint-hi arguments probatoris que confronten el contingut amb l'experimentació agrícola o afegint-hi contingut basat en testimonis orals o visuals adquirits per l'experiència personal.

M.A. Martí, en l'estudi que acabo d'esmentar, assenyala que Pietri de Crescenzi (1233-1320) és emprat, però el tema, vist el que hem vist, és saber si les referències als clàssics són directes o mediatitzades per altres textos. Una empresa gegantina.

Podem dir que l'obra d'Agustí és doncs una mescla de traducció, d'adaptació i d'obra personal; per això cal abandonar l'acusació nua i pelada de plagi. També s'ha de reconèixer que la diferència entre una traducció (literal) i una versió (lliure) pot ser difícil d'establir parlant d'una obra sencera. I cal afegir-hi encara que queda oberta sempre la possibilitat de descobrir alguna peça més en l'elenc de les fonts.

La mateixa Martí ha fet avenços en revelar-nos els deutes d'Agustí amb el contingut del manuscrit de París BnF-291 (Bibliothèque National de France) i el ms. BC-754 de la Biblioteca de Catalunya de Barcelona, que jo mateix he editat amb el títol de Libre de plantar vinyes e arbres (Luna-Batlle, 2011), i que ha estat editat abans per Thomas M. Capuano (2009) i per Rosa Maria Raich en un treball inèdit. Mitjançant l'anàlisi comparativa dels anomenats pal-ladis arromançats amb el llibre d'Agustí, M.A. Martí (2008: 291) prova que cal afegir aquell manuscrit conservat a París i la seva versió de Barcelona a la llista de les fonts dels Secrets que elaborà Giralt (2002).

Ara, també és important identificar les obres agronòmiques anteriors als Secrets que no s'hi esmenten o no hi tenen influència directa i entre elles n'hi ha dues de cabdals de la història de l'agronomia europea, que sabem que tingueren una gran difusió en els anys anteriors a l'obra d'Agustí, i que se'ns fa difícil 
d'imaginar que Agustí no coneixia. ¿Per quina raó, doncs, no les té en compte quan Agustí es planteja de fer un llibre de dimensions considerables, gairebé una enciclopèdia dels coneixements agrícoles? Podríem considerar que hi hagué qüestions ideològiques que «censuraven» determinades obres d'una línia de pensament diferent a la dels membres del Temple.

La primera d'aquestes grans obres que Agustí ignora és la de Gabriel Alonso de Herrera, Agricultura general, de 1513, i molt reeditada (16 edicions durant el segle XVI). Tampoc no s'hi esmenta la que potser és l'obra agronòmica francesa més important, la d'Olivier de Serres, Le Théâtre d'agriculture et mesnage des champs, que apareix el 1600, editada 17 anys abans dels Secrets. De tota manera, no hem de descartar del tot de trobar rastres d'aquestes obres en Agustí. Indiquem aquí només una pista que caldria seguir per arribar a saber si Agustí beu, sense dir-ho, d'Herrera i de Serres o bé si el català en prescindeix del tot. Per posar-ne només un exemple breu, en relació amb els gossos esmenta que el gos del pastor convé que sigui blanc:

Convé que sia blanch, perquè lo pastor lo puga més fàcilment veure quant corre darrera lo llop y conèixer-lo a la tarde y matinada. (76v)

I Herrera ja havia dit el mateix, però essent més explicit i en un estil d'escriptura ben diferent:

Y para andar con el ganado procuren los perros blancos, porque algunas veces acaece asirse de noche con algun lobo, y por ser todos de un color, o casi no sabe determinar el pastor qual es perro, o qual es el lobo, y a las veces con aqueste error piensan herir al lobo, y hieren al perro. (Herrera: 348 )

Però sembla clar que la font directa per a Agustí no és Herrera sinó Estienne et Liébault (deixant de banda l'origen del tòpic):

\begin{tabular}{|l|l|}
\hline Estienne i Liébault (edició de 1597, p. 152) & Miquel Agustí (f. 176v) \\
\hline $\begin{array}{l}\text { Le chien de berger ne doit estre tant gros et } \\
\text { pesant que celuy de la metairie. Toutes fois }\end{array}$ & $\begin{array}{l}\text { Lo ca del bestiar de llana no ha de ser } \\
\text { axí gran ni tant grave com aquells de la }\end{array}$ \\
aussi fort et robust eet aucunement prompt et & guarda de la casa, sinó forts y robustos \\
legert. Car on le prend pour combattre et pour & y algun poch prompte y llauger, que sia \\
courir, attendu qu'il doit guetter et chasser les & per a combatre y per a corre per lo que \\
loups et s'ils emportent quelque chose les suyu- & ells han de fer guarda y centinella con- \\
re et leur offer la proye, parquoy vaut mieux & tra los llops y de donar-los la caça y si \\
pour ceste fin qu'il soit plus long que court et & se'n pòrtan alguna cosa seguir-los y \\
quarré, car toute beste de corps long est de plus & fer-los deixar la presa y per aquesta \\
grande et meilleure course qui la coust et qua- & causa és millor que lo ca sia prest llarch \\
rré. Doit estre blanc, à fin que le pasteur le & que no curt ni quadrat. \\
puisse plus facilement discerner d'entre les & Convé que sia blanch, perquè lo pastor \\
loups et le cognoistre tant en l'endroit de la & lo puga més facilment veure quant \\
nuict qu'on dit entre chien et loup que mesmes & corre darera lo llop, y coneixer-lo a la \\
en la grande obscurité d'icelle. & tarde y matinada. \\
\hline
\end{tabular}




\section{La part original dels Secrets}

La part que podem dir que és original d'Agustí és força petita en extensió. Tanmateix, són fragments importants, pel relleu de la temàtica i de les observacions en relació amb el paisatge rural i la cultura material coetanis. Ja en vam parlar a Luna-Batlle (2007). Aquí en faré només un recull temàtic amb alguna referència, sense pretendre ser exhaustiu:

\subsection{En relació amb els tipus de clima i de sòl}

Agustí esmenta el que és propi del país: «est Principat de Cathalunya y Comtats de Rosselló y Cerdanya, [té] part de terra calenta, altra part trempada, altra freda, y gel-lada, altra de vents forts a fi que tots los territoris no són de una ygualtat» (f. 77r) per indicar tot seguit que aquí «les terras fructifiquen més a unes parts que en altres, y unes produeixen lo pur forment, y fan gentil pa y altres delicats menjars per lo viure dels hòmens» (f. 77v-78r).

En relació amb allò que cal conrear hi ha una descripció que divideix el territori català en cinc regions climàtiques:

serà clima y terretori fret lo Comptat de Puigcerdà, la Seu de Urgell, Vich y les montanyes ahont no y poden viure los olivés ni les serments. Serà clima y terretori trempat lo Comptat de Rosselló, Gerona y altres parts ahont vihuen los olivés y serments y no y poden viure los torongés, poncemés y llimoneres, sinó ab gran treball per lo fret. Serà clima y terretori calents València, Mallorca y part del Bisbat de Barcelona y Tarragona, ahont ultra dels olivers y serments, vihuen torongers, ponsemers y llimoneres, sens danyar-los molt a tart lo fret. (f. 80r)

\subsection{En relació amb la verema}

Sembla que també és una aportació d'Agustí l'esment a la manera particular de premsar el raïm que tenen el pagesos del Rosselló, que devia veure personalment:

En lo fer lo vi en la tina, se usa en Rosselló posar la verema ben pitjada en la tina, y després de aver acabat de posar tota la verema, no la pítjan més, y veig que en Cathalunya se usa pitjar la tina matí i vespre. Tant quant està lo vi a la tina, jo tinch per millor no tocar-la, perquè ab lo girar que fan en Catalunya matí i vespre, se esbrava y pert lo vi la fortor. Per tant en Rosselló són més forts los vins que en ninguna part de Catalunya, ab tot entenc que lo terratori ne és la causa. (f. 99v)

\subsection{En relació amb l'elaboració de vi grec}

Sense tenir en compte què s'ha entès al llarg de la història per vi grec (per als clàssics era un vi bullit al qual s'afegia aigua de mar i aromatitzadors com xufla i canyamel, segons Cató; Eiximenis ens en dóna notícia), Agustí es refereix a com es feia en el monestir de Banyoles, a partir de la situació personal, segons diu, de 
ser al servei del noble Antic de Villalba, l'abat, i amb una verema que es feia als «prats del castell de Porqueres» (f. 100v).

\subsection{En relació amb l'arròs}

Indica que se'n fa a València i a la zona de Torroella de Montgrí del bisbat de Girona (f. 85r).

\subsection{En relació amb les mesures}

En els folis dedicats a acanar les terres, les referències a les mesures catalanes hi semblen del tot necessàries i esmenta les del Rosselló, la Cerdanya i el Conflent, la vessana i la mujada (f. 136v), i té en compte un tema central per a l'intercanvi i el comerç, el de les equivalències entre mesures de diferents llocs:

en lo comptat de Rosselló de les mesures de les terres se mesuren per ayminades y en dit comptat la ayminada són 1.500 canes de Mompeller, que la cana són deu palms de cana barcelonesa y en lo mateix comptat en lo Vallespir són 1.600 canes de Mompeller la ayminada, y en lo comptat de Sardanya y Conflent mesuren les terres a jornals, que lo jornal és lo conreu de un parell de bous. (f. 137r)

Fins i tot apareix una mesura de superfície poc coneguda, la punyerada, que el DCVB només exemplifica als Secrets d'Agustí, que corresponia a la porció de terra que se sembrava amb una punyera de gra, mesura de capacitat ja documentada des del s. XI (DECat, VI, 876).

\subsection{En relació amb la mel}

També llegim una referència a dues poblacions del Rosselló en relació amb la mel:

La mel blanca no és de menor bondat que la rossa, perquè té los altres señals de bondat, com és aquella de Salsas, Òpol y la del entorn del País de Narbona, que és molt blanca y prou ferma y millor sens comparació que tota altra sort de mel. (f. 188v)

\subsection{En relació amb les gallines}

S'hi esmenta una pràctica amb les gallines que l'autor sap pel seu majordom:

Lo nostre majordom, molt grave y rigurós, les banyava ab aygua per a refredar-les de aquella calor o las posava sota de una cova fent-les dejunar tres o quatre dies. (f. 153r)

\subsection{En relació amb les ovelles}

Agustí també es refereix a Catalunya, encara que molt breument, en el capítol dedicat a la ramaderia ovina en relació amb la qual hi ha «coses singulars y útils a 
la draperia que se fa en aquest Principat de Cataluña, Rosselló y Serdanya y dels preciosos formatges y axí de la delicada carn de moltó.» (f. 172r)

\subsection{La construcció de xemeneies}

No és un tema menor, en un país de forts vents com el Rosselló, però no és usual trobar en un text agronòmic una descripció tan detallada de la construcció de la xemeneia de les cases, més en una obra que tot i donar importància a l'edificació de la casa, com feien els geopònics clàssics, no dedica gairebé gens d'espai a detallar com s'havien de fer les construccions de l'àmbit agrari, malgrat les diverses referència a la distribució i a l'orientació de les cambres (Garriga, 1988: 11). L'especial atenció a la xemeneia va acompanyada d'il-lustracions, que hem de pensar que són originals (mentre no tinguem més informació), i d'una referència directe a l'entorn de Perpinyà que coneixia Agustí:

Lo autor de aquest llibre, ab la ximanella té feta de aquest modo en la casa té feta en la Església del Temple de Perpinyà, lo any mil sis-cents y onze, ab molt felice succés. Perquè en cinch anys que ha que és feta, en totas diversitats de vents que ha fets, sempre ha tret molt bé lo fum per alt, sens may tornar atràs, no obstant tinga dalt padrastre del campanar de la dita església, y la casa del noble don Francesch Taqui, que és més alta, y per ser cosa tant convenient, no sols a la casa de la agricultura de la campanya, però encara en totes les cases particulars de les ciutats y viles, ensenyaré assí alguns modos de ximanella que seguint aquest modo que baix explicaré, sempre per qualsevulla vent fassa trauran lo fum per alt, sens tornar atràs, encara que dalt tíngan qualsevol padrastre de algunes cases. (f. 148r)

\section{En la història de la llengua}

El llibre d'Agustí no ha estat explotat d'una manera completa pels grans diccionaris, tot i que és una obra que ha cridat l'atenció des dels primers moments de la lingüística contemporània: Marià Aguiló ja treu material de l'exemplar de la Biblioteca de Catalunya per a l'anomenat Diccionari Aguiló, material recollit a la segons meitat del XIX (Colón \& Soberanas, 1986: 187), i s'hi refereix amb l'abreviació «Prior». Es considera «una font de primera categoria per als diccionaris d'Alcover-Moll, de Fabra i de Coromines», en paraules de Joan Solà; i el DCVB està ple de citacions de l'obra d'Agustí, per bé que no s'hi fa un buidatge complet de tot allò que hi fóra útil. Joan Coromines el té en compte en el seu DECat, però sovint aprofita la informació que ja havia aplegat el diccionari d'Alcover i Moll sense que sembli, almenys en alguns casos, que hagi anat a la font.

Cal dir que una de les motivacions per escorcollar el llibre és la cerca de dialectalismes, com passa amb els llibres d'agricultura, que podem anomenar textos il-literaris sense pretensions de creació artística i per això sense gaire influència dels models de correcció o de moda operants. I en efecte Agustí fa servir mots propis del rossellonès i la zona de transició del català central al septentrional. Prats i Rossich (1988) ja van fer una introducció a la llengua dels Secrets, amb força detalls i amb una classificació temàtica, però no deixa de ser una aproxima- 
ció. L'estudi complet de l'obra, doncs, encara cal fer-lo perquè hi ha múltiples proves que se'n poden treure observacions interessants i novedoses.

Un cas, entre molts d'altres encara no observats, és el de cervesa. El mot (un lexema gal d'ètim llatí: cervoise està documentat en francès antic al segle XII, en occità antic és cervesa) està enregistrat en el DECat de Joan Coromines informant-nos que la primera documentació és del s. XIII (apareix a les Vides de sant rosselloneses, text que l'eminent lingüista va estudiar descatant-ne el fet que s'hi recull la llengua dialectal rossellonesa de l'època) i que també n'ha trobat un exemple en una traducció o versió feta per un mallorquí de 1380 de la Questa del sant. No diu res però que aparegui en els Secrets d'Agustí, de manera que tenim un exemple de l'època moderna que ens completa la documentació coneguda, que passava de l'època medieval a la contemporània. Hi ha indicis, com aquest, que Coromines no acudí directament a buidar els Secrets sinó que se serví dels exemples que ja apareixen en l'Alcover-Moll.

A més de les formes comentades per Prats i Rossich (1988), hi trobem (estalviarem en aquest punt les remissions) les formes populars decernir, distil-lar o terratori; les formes clàssiques que possiblement són arcaismes en el temps d'Agustí faitís 'fet a posta', flum 'riu'. Altres mots tenen una història més complexa perquè s'han deixat de fer servir en unes regions mentre que en d'altres s'han continuat usant en la llengua parlada. Dos exemples: dejús (DCVB, s.v. dejús: «Rosselló, Conflent, Olor, Mieres, Cardona. En aquestes regions i poblacions citats és viu encara el mot dejús en el llenguatge parlat; a moltes comarques ha desaparegut i el coneixen només els lletraferits»), semal «portadora, cub que se sol destinar a transportar la verema», avui només viu al nord-est del domini. I formen un conjunt important els dialectalismes que ja ho eren a l'època d'Agustí i que s'han conservats fins avui: enviar «empassar», èrpol «rastell», grupot «carpó de les gallines» (avui grupó a l'Empordà), rantell «mosquit», rega «solc», ribera «riera, riu», ximanella «xemeneia», etc.

No cal dir que els castellanismes, com tots els textos de l'època, conformen un conjunt també important del lèxic de l'obra: bisonyo, caldo, cuidado, límpio, manso en són exemples. Joan Veny va acudir al llibre d'Agustí en el seu estudi ja clàssic «Sobre els castellanismes del rossellonès» (Veny, 1978). Jo mateix vaig estudiar els casos de polimorfisme, que ens indiquen una llengua en evolució i una escriptura tolerant amb les diverses opcions lingüístiques. Així apareixen albercoc i albricoc, canasta i ganasta, elra i eura, escorrialles i escorrilles, olm i i om, palm i pam, oreneta i areneta, ós i onso, etc. Aquesta llibertat normativa és fructífera als ulls de l'investigador ja que ofereix múltiples ocasions d'observar com devia ser la llengua parlada i quines forces estaven actuant en la dinàmica de l'escriptura. Els Secrets ens il-lustra el que ja ha remarcat Joan Solà observant tant els textos com la preceptiva de tres obres gramaticals i lèxiques de la segona meitat del s. XVII:

Tant aquestes obres com d'altres del gènere ofereixen una vacil-lació considerable tant de formes com de grafies: en part es tracta de lapsus o deficiències d'impremta, i en part, d'acceptació conscient de variants. [...] tot plegat indica que el món 
escolar (tant el pedagògic com l'editorial) estava bastant deixat de la mà de Déu, almenys pel que fa als escrúpols lingüístics. (Solà, 1889: 9)

És una època en què les vacil-lacions d'escriptura de tota mena campen pertot, però no sabem si la variació interna del llibre d'Agustí és més accentuada que en obres redactades i estampades en circumstàncies més favorables a una major cohesió lingüística interna. Per una altra banda, haurem d'estudiar perquè hi ha alguns mots dels quals només tenim referències en els Secrets, com pipir 'piular el poll de la gallina'.

Els llibres d'agricultura històrics són una font molt fecunda de coneixement de la llengua popular, però també dels avatars de la llengua culta. Podem indicar, per exemple, que ningú no ha notat que Agustí fa servir alguns cultismes que els grans diccionaris fan aparèixer molt més tard. És el cas del mot convulsió que l'Alcover-Moll exemplifica en els Croquis pirinecs de Massó i Torrents, obra del 1896, i que Coromines fa recular al 1803. Agustí ens il-lustra un ús del mot de dos-cents anys abans: «la aygua que ne exirà és excel-lent per fer untament y fomentació a la paralícia, convulsions.» (f. 127r, i repetit al marge).

Pel que fa al rendiment lingüístic, un cas paral-lel és la gran obra castellana d'agricultura, la de Gabriel Alonso de Herrera que, en paraules de Eloy Terrón (1996: 37), no va ser ni un poeta ni un místic sinó un home lliurat a posar en un castellà ingenu i vacil-lant allò que havien estat fent els pagesos a Castella per produir el blat, l'ordi, la civada, el vi, l'oli, el formatge, la carn, la llana, el lli, etc. amb què s'alimentaven i es vestien. Així al cap de quatre segles els camperols castellans encara es poden reconèixer en el llenguatge d'Herrera, perquè va recollir què era l'agricultura del seu temps, amb la seva tradició cultural i etnogràfica. Agustí i Herrera s'acosten en això: podem dir el mateix d'Agustí que el que subratlla C. Baranda (1989: 99) en relació amb Herrera: «la asombrosa riqueza de su vocabulario».

\section{En la història sociolingüística}

L'obra d'Agustí només s'estampa un cop en la llengua original. Totes les edicions posteriors es fan en castellà. Aquesta és una primera dada rellevant per a la història del contacte de llengües a Catalunya i els espais diferents que ocupen en cada moment històric. Hem de posar el nostre cas en la línia del manteniment de la llengua catalana en part dels tractats tècnics i científics, especialment els pràctics, i també veure'n les diferències en relació amb altres camps. Per exemple: molts llibres mèdics continuen redactant-se en català malgrat la posició dominant del castellà, i són abundants en una època en què les pestes són una preocupació sanitària i mèdica de primer ordre. Segons Lluís Cifuentes (2001: 110) el dels tractats de pesta «fou pràcticament l'únic gènere científic - al costat dels llunaris i els tractats d'aritmètica comercial— que continuà imprimint-se en català durant l'època moderna». I en efecte, sabem que la substitució lingüística no és un fenomen homogèniament progressiu en tots els àmbits d'ús sinó que en cada espai comunicatiu hi ha velocitats diferents i factors que expliquen aquests ritmes 
també diversos, com ja ha mostrat, per exemple, Anna Maria Torrent per al cas de la predicació en el segle XVII (Torrent, 1988). Aquests tempos diferents es poden també constatar en el gènere de les memòries i llibres de masover, que s'escriuen en català fins ben entrat el XIX i a partir de mitjan segle, amb la Renaixença incipient, aquesta mateixos pagesos passen a escriure en castellà.

És també rellevant el fet que a l'època d'Agustí és freqüent que els llibres escrits en català hagin de justificar l'ús de la llengua del país, símptoma evident que la tendència dels temps és imprimir en castellà, tant per raons de poder ideològic i polític com per raons de mercat. Agustí no s'estalvia aquesta justificació per escriure en català:

encara que moltes persones, de més subtil ingeni, y en més aventatjada experiència han escrit diverses coses y secrets de la agricultura, casa rústica y pastoril, uns en llengua llatina, altres en llengua castellana, altres en llengua italiana, altres en llengua francesa y altres en diverses llengües, vehent que ningú se és ocupat a escriure en nostra llengua cathalana y pot ésser que los que vuy exercítan la dita agricultura en nostra Cathalunya no acèrtan en fer y posar les coses quel se deu, causant-ho per ventura lo no entendre les llengües. (f. vir)

I és molt explicativa la justificació de Pere Gil, quatre anys més tard (1621), quan tradueix el Kempis, una obra destinada a la pietat i amb la pretensió d'obtenir una màxima difusió, citació que ens permetem de recollir de la Història de la llengua catalana de Pere Marcet, on no és marginal l'observació que la llengua moderna ja no era la mateixa que la medieval:

Aquest llibre [Menyspreu del món], compost y estampat en llatí, se troba traduït en totes les llengües vulgars esteses entre christians [...]De la versió cathalana sols he vist un exemplar estampat en lo segle passat [...] en llengua antiga que era en bona part limosina, ara no usada en Cathalunya [...] Alguns per ventura indicaran que en aquest temps no era necessari imprimir-se lo present llibre en esta llengua, puis la castellana és casi universalment estesa. Però com se veja y toque ab las mans que acceptades algunes pocas ciutats com són Barcelona, Tarragona, Gerona, Tortosa y Lleida, y algunas pocas vilas, com Perpinyà, Vilafranca de Panadès, Servera, Tàrrega, Fraga, Monçó y semblants, que estan en camins reals, en las altres demés ciutats, vilas y llochs no és ben entesa la llengua castellana de la gent comuna, y ningunas donas la úsan, ans bé la llengua cathalana entre algunas llenguas dins del Regne de Aragó y de França y és parlada casi en tot lo Regne de València y en las Illas de Mallorca, Menorca, Iviça, y en part de la Serdenya, per ço me ha paregut ser de glòria de Déu verter est llibre en las paraulas més planes y comunas de la llengua cathalana per a que tota la gent puga d'ell aprofitar-se. (citat a Marcet, 1987: 301-302)

En l'àmbit de la impremta, del qual parlarem més endavant des del punt de vista estricte de la producció, durant el segle XVII el català va deixant lloc al castellà, sense que el llatí en quedi al marge:

[...] la creixent castellanització de la producció impresa culta continua imparable. El català queda cada cop més relegat als gèneres de consum o utilitaris, els de venda 
segura i probablement majoritària ja descrits: catecismes, devocionaris i butlles, goigs, beceroles, franselms i isopets, almanacs i quaderns de comptes, avisos gremials i oficials i, a partir d'aquest segle, una part dels fulls de notícies. En rigor, més que de llibres es tracta d'opuscles, fulls solts i volums petits, en general d'impressió poc acurada. [...] Per contrast, les obres de prestigi cultural es vehiculen en castellà o en llatí, com les literàries de més volada. [...] Per fer-se una idea de la presència de les llengües en l'edició basti l'eloquència d'aquestes xifres aportades per Jordi Torra: sobre un total de mil llibres impresos a Barcelona al segle XVII, 672 són en castellà, 222 en llatí i 112 en català. La impremta i l'edició catalana, en suma, es desvinculen progressivament de la llengua del país.» (Llanas, 2002: 236-237)

El llibre d'Agustí il·lustra de manera diàfana el procés: la primera edició és el 1617 en català i la segona, el 1626, ja és en castellà, amb la dada significativa que és el mateix Miquel Agustí que en fa la versió, i apareix a Perpinyà: el procés de castellanització de la impremta és ben constatable.

\section{En la història de la impremta}

L'impressor, Esteve Lliberós, és de Barcelona, i Llanas (2002) n'ha estudiat la producció. Lliberós no era un impressor especialment vinculat a les instàncies oficials, com ara la Generalitat; en canvi edità tres tractats de temàtica diferent. Ignorem per quina raó va rebre l'encàrrec d'estampar una obra que procedia d'un prior de Perpinyà de l'orde del Temple. Quant als gravats són tots copiats del llibre d'Estienne, llevat del de la portada i els relatius a les xemeneies, a mà alçada, amb el resultat d'una qualitat inferior en el traç del dibuix. Una curiositat és que

Figura 1. Gravat de la Maison Rustique d'Estienne et Liébaul

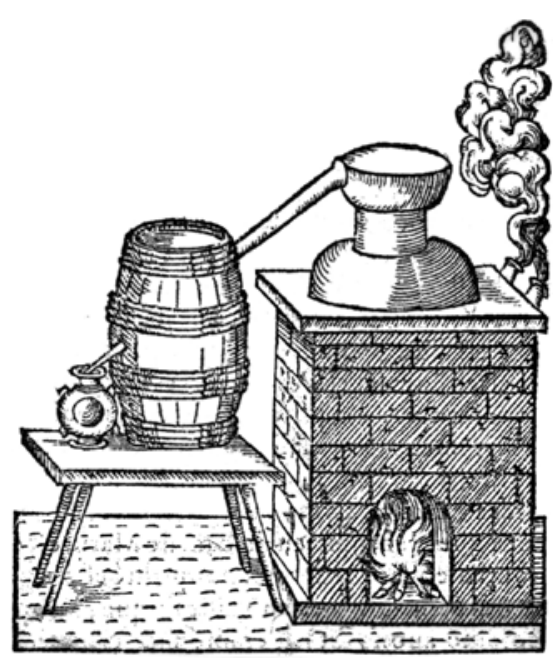

Figura 2. Gravat dels Secretes d'Agustí (f. 118r)

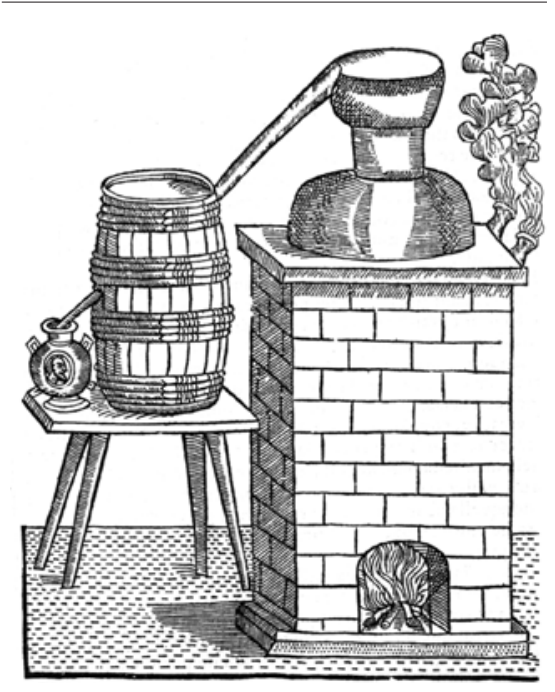


en el gravat del foli 118r, el gravador que copia hi afegeix el dibuix molt simple d'una cara en l'atuell que recull el destil-lat: un personatge amb barba que podríem imaginar que es tracta d'un retrat caricaturesc del mateix Agustí o bé del gravador. Un altre detall de la impressió és la presència central de la creu de Malta en el gravat de la portada, que es repeteix en les portada dels llibres segon i tercer, tots els que conformen el volum, com també en el primer full de les taules. S'hi fa patent doncs que es tracta d'una obra de l'orde de la creu de Malta. Altres detalls gràfics poden ser significatius, com les caplletres, que recorren tant a la imatgeria religiosa com a la profana.

Figura 3. «Forma de la ximanella de la casa de la agricultura cuadrada» (f. 149r)

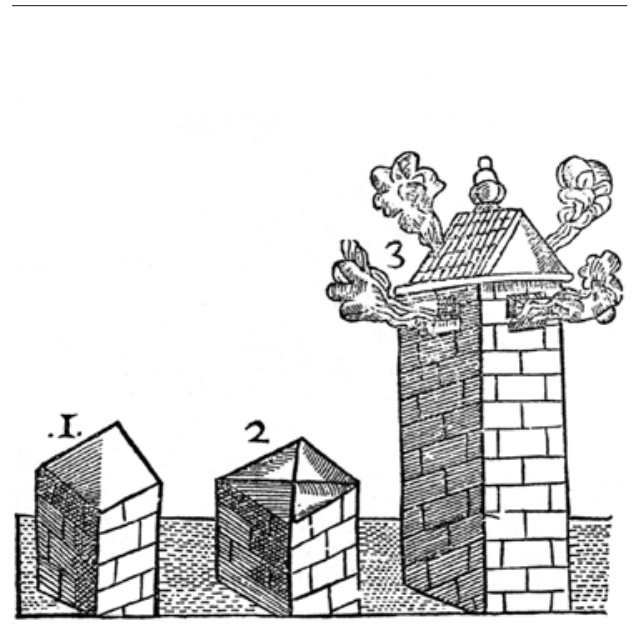

Figura 4. «Forma de altra ximanella quadrada» (f. 149v)

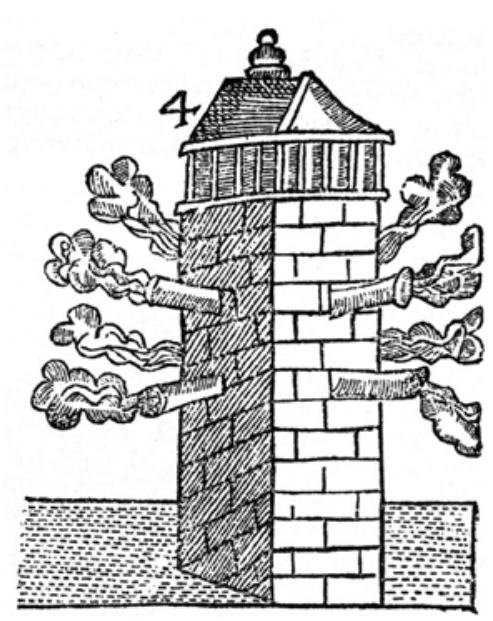

\section{En la història de les mentalitats i les ideologies}

El títol de Secrets desperta un interès especial en el sentit que el mot secrets no apareix en els precedents ni en les obres coetànies ni posteriors dedicades a l'agricultura. ¿És un indici d'algun vincle especial amb una determinada ideologia? ¿És una moda vinculada al Barroc?

Ara: això pot ser un detall poc significatiu que es podria resoldre arribant a la conclusió que era una moda de l'època sense més transcendència. Però això caldria potser posar-ho al costat — no vull dir que hi hagi d'haver correlacions - del fet que Agustí era prior d'un temple de l'orde de Jerusalem. Xavier Torres apunta aquesta idea:

La Contrareforma i, en general, les reformes religioses de l'època moderna no feren sinó reblar el clau; i difondre encara més, i amb l'ajut de la impremta, el paradigma del pater familias cristià. Es propagà, aleshores, una mena de tractats agronòmics que no diferien pas gaire d'un catecisme moral. Aquest fóra, altra- 
ment, el tenor de la coneguda [...] obra de fra Agustí, el Llibre dels secrets d'agricultura (1617), escrit per a il·lustració o instrucció de «lo bon pare de família de agricultura»; és a dir un pagès emmullerat, i amb mainada, però també amb «criats y treballadors y llurs famílies [respectives]. Així, a més d'uns quants "secrets" o coneixements agrícoles, Agustí enumera, sobretot, els deures cristians del pater familias, el qual, tot i la seva posició familiar avantatjada (o precisament per això mateix), haurà de ser el primer a donar exemple. (Torres, 2000: 64)

Ara: aquesta presentació del llibre d'Agustí no té en compte que la part dedicada a les tècniques agràries, a la menescalia, etc. és, sense punt de comparació, molt més important que no pas la dedicada al diguem-ne alliçonament moral. Per altra banda és un tret característic dels llibres d'agronomia clàssics tenir en compte el comportament exemplar de qui governa una casa rural. Cató, entre els més antics dels agrònoms clàssics, per exemple, al segle II aC, en referir-se al majordom (l'equivalent en el llibre d'Agustí al pater familias), diu:

Aquests seran els deures del majordom. Que tingui bon maneig; guardi les festes. No toqui el que és d'altri; servi el que és seu curosament. Sobresegui les qüestions de la família: si un fa en res falliment, el puneixi a les bones segons el dany. Que la família no ho passi malament: no fredegi, no famegi; que l'exerciti bé en el treball, i més fàcilment l'apartarà de cosa dolenta o inconvenient. Si el majordom no vol, no es farà mal: si hi ha estat consentidor, l'amo no el deixi impunit. Per cosa ben feta, mostri's agraït, per tal que sigui plaent a altri de fer bona feina. El majordom no sigui trescador: sigui sempre sobri, mai no vagi de platxeri enlloc. Faci treballar la família, en tingui cura: ço que l'amo mana sigui fet. [...] No consulti arúspex, àugur, endevinador, ni astròleg. No rapinyi a l'esplet, que això és miseriós. Curi de saber fer tota feina de camp, i en faci sovint, sols que no es cansi: així sabrà per experiència el treball que pertoca a cadascun de la família, i ells el faran de bon grat. Si fa tot això, menys s'abellirà a fer tombs, guanyarà en sanitat, i dormirà més a pler. Es llevi, el primer, del llit, i vagi, el darrer, a dormir; i vegi abans si la granja roman closa, si cadascú jeu al seu lloc, i si els animals tenen recapte. (Cató: 13-14)

Cató i Agustí diuen respecte a qui governi una casa agrícola coses semblants, i la referida a l'hora de llevar-se i la de colgar-se és idèntica:

que no sia vagabundo, castioner, tavarner, antes bé sàpia refrenar lo seu apetit y los hòmens qui li estan subjectes, no dexant anar las cosas a mal andar, ni mal andar ni a total ruyna; sia lo primer qui·s llevarà y lo darrer qui anirà al llit [...] (f. 2r)

És clar, però, que en Agustí s'hi afegeixen elements atribuïbles a la moral catòlica, com ara la d'evitar la blasfèmia: «y sobretot ha de ser molt observant la sua paraula, y no ha de jurar de Déu, per donar bon exemple a tota sa família» (f. 2r). Caldria avaluar amb més precisió, doncs, el pes del llibre en l'educació en la moral de la Contrareforma tenint en compte el conjunt, perquè segons la meva impressió, no hi ha elements suficients dins l'obra d'Agustí per equiparar-la a un catecisme moral, tal com afirma Xavier Torres, malgrat les indiscutibles pinzellades d'orientació cap a la moral catòlica. 
La qüestió ideològica té una abast més general i més profund. Caldria veure si en Agustí hi ha un censura en relació amb les obres agronòmiques més avançades, tècnicament i ideològicament, com el cas d'Olivier de Serres, del qual, a primera vista, no sembla que hi hagi rastre. Serres ja havia publicat la seva obra en francès quan Agustí pren com a referència el llibre d'Estienne, també escrit en francès, de manera que no podem argüir que no coneixia Serres a causa de la llengua. Però val la pena observar que Estienne competia amb el seu coetani i compatriota Olivier de Serres, aquest un autor amb una mentalitat molt més científica i experimental, de ruptura, segons Pierre Lieutaghi (2001, 10-11):

Considérer le Théâtre [d'Olivier de Serres] au regard de la production agronomique de son temps conforte cette impression de rupture. Il suffit de mettre en parallèle quelque passage que ce soit d'Olivier de Serres et son analogue dans $L a$ Maison rustique des médecins lyonnais Estienne et Liébault. [...] La Maison rustique, jusqu'en ses éditions du Xvinte siècle, est l'héritier d'un empirisme routinier souvent indistinct de la croyance, quand le Mesnage des champs [de Serres], s'il fait une large part à l'empirisme comme acquis de l'expérience traditionnelle (c'est la définition première du terme), le pose comme matériau perfectible, un tout cas sujet à interrogation critique, dans un regard que cette distance même établit comme scientifique.

Poc més endavant Lieuthagi (2001: 11) explica com Estienne i Liébault són els continuadors de les herbaria medievals mentre que Serres

ne se compromet nulle part avec aucune magie, fût-elle blanche; c'est l'oeuvre d'un homme qui, à l'instar de Calvin, exclut toute relation, même implicite, avec les commerces suspects d'une Église où, à force d'évoquer Satan et ses innombrables pouvoirs, on incite à l'invoquer.

Remarquem que més enllà del passatges (escassos) de doctina catòlica, hi ha una manera d'entendre la natura i l'agricultura que és la continuació del medievalitzant Estienne, ben entès que totes dues línies són vehicles de transmissió de la cultura agronòmica clàssica, amb el mateix objectiu principal d'incidir en la manera de treballar la terra, d'organitzar les unitats de producció agrícoles i de veure el món, incidència que té en compte tant la ideologia com l'experiència i la tècnica, en proporcions diverses.

Emili Giralt (2008: 356) n'ha observat aspectes generals del contingut per situar el llibre en el paisatge ideològic quan en relació amb la història dels empelts de la vinya fa aquest comentari:

Al llarg del Llibre, però, el Prior Agustí, amb la seva dèria d'exhibir lectures erudites, accepta sense crítica les fantasies contingudes en la literatura pseudocientífica emparentada amb l'astrologia, la màgia i el secretisme propis de la geopònica de l'hel·lenisme tardà. (Giralt, 2008: 356)

I en la conclusió d'aquest mateix article, Giralt (2002: 337) insinua que Agustí s'ha sotmès a l'autocensura mitjançant aquests indicis: Agustí evita «certes al- 
lusions a l'Església, a la sexualitat, a la bruixeria o als encantaments, temes en què els autors de la Maison rustique es movien més còmodament que no pas el nostre religiós que escrivia en un temps i un país on la contrareforma catòlica estava en plena vigoria.»

\section{Destinataris i recepció}

S'ha dit diverses vegades que els Secrets d'Agustí van tenir una gran repercussió i van adquirir una fama considerable. Segons Lluís Cifuentes:

[...] si els tractats que circulaven durant els darrers segles medievals, tant en llatí com en català, anaven adreçats primordialment a la burgesia que tenia cada cop més possessions rústiques, a partir de la segona meitat del segle xv, com veiem en els tractats d'Herrera o, de forma molt evident, en el d'Agustí, cerquen un públic de propietaris rurals que valora l'autosuficiència de l'explotació agrària. (Cifuentes, 2002: 89)

El mateix Agustí, en relació amb el tema de la cacera, descarta que agricultor pugui tenir interès en les activitats cinegètiques:

Tractaré solament en aquest lloch dels [cans] de la guarda de casa y del bestiar y deixaré los de la caça per los nobles y gentils hòmens per ser la caça cosa tan delitosa. (f. 176r-176v)

I en efecte, en els dos folis que segueixen la presentació del tema tracta dels gossos que vigilen la casa rústica i el gossos pastor, com cal tenir-ne cura i com tractar-ne les malalties, sense cap atenció als gossos de cacera. Descarta així que el llibre vagi adreçat als nobles i l'orienta estrictament als agricultors.

Adopta exactament la mateixa posició que Herrera, aquest molt més explícit en la justificació:

Cap. XII. De los perros. Son muy necessarios para la guarda del ganado los canes, o perros, y aun de las casas, aqui no es mi intencion decir de los perros de caza, ni de los alanos de carniceros, salvo de los mastines para el campo, contra los lobos, y ladrones, y para la guarda de las casas, que aver de decir de los cazadores, no me parece para este tratado. Pues no ay cosa que menos convenga al labrador que la caza. No digo tampoco que no cacen algun rato, mas es de tal condicion la caza que engolosina, y trae a si al que comienza a darse a ella, y no ay cosa que tanto eche a perder al labrador y aun a quien quiera, que nunca de cazador se vido hombre rico, por esso los perros de caza dejemoslos a los ricos, a los cavalleros, y a personas de renta, a los holgados que no tiene que hacer, y es mejor que ejerciten la caza que otros vicios en el poblado. (Herrera: 347 )

El llibre doncs no va adreçat als que viuen al «poblado» (lloc de vicis, per altra banda), com tampoc el d'Agustí.

Lluís Cifuentes (2001: 294) diu, mostrant-se d'acord amb el parer de Lluís Argemí i M. Mercè Gras Casanovas i Maria Àngels Pérez Samper (1999), que en 
comparació amb els precedents el llibre d'Agustí «és adreçat ja a un públic molt més ampli, que ha constituït fins a èpoques ben recents, mercès a les seves múltiples reedicions en castellà durant els segles XVII i XVIII, el manual de referència del camp català en agronomia, medicina pràctica i menescalia.» Gras i Pérez afirmaven que al segle xx «es troba en multitud de cases de pagès». Una altra aportació és la de Pasqual Bernat que es refereix a la recepció del Secrets, després d'observar que no recull tècniques innovadors, en aquests termes:

La utilitat del llibre d'Agustí estaria, doncs, no en el seu aspecte tècnic, sinó precisament en el que té de descripció d'un mode de vida, d'una forma de fer i pensar amb la qual es van identificar moltes generacions de pagesos. (Bernat, 2008: 39)

La utilitat del llibre, sigui quina sigui, com diu Bernat, no pot explicar tota sola el perquè de l'èxit de l'obra. Hi hem d'afegir un factor que fa temps que s'ha remarcat: el de la vigoria i extensió dels masos durant una determinada època, en el concepte d'unitat econòmica i de vida amb un certa capacitat d'autosuficiència. Pierre Vilar deia en relació amb la repercussió de la Sentència de Guadalupe (1486):

La masia, alliberada jurídicament, és prou forta per a defensar-se [dels bandolers]. Si el bandidatge és una mena de lluita entre masia i castell — cosa que resta per demostrar en detall - això no pot amenaçar, en tot cas, els resultats de la gran revolució agrària. L'esdevenidor ho demostrarà: la petita noblesa rural s'anirà extingint; Catalunya a la fi del vell règim, comptarà un noble per cada 300 habitants (Castella la Vella, 1 per cada 3); la masia pagesa subsistirà més pròspera que mai als segles XVIII i XIX. (Vilar, 1979 [1962]: 289)

A Catalunya el mas i el masover, un mercat potencialment gran, pot ser el destinatari d'un llibre pensat per a aquestes unitats rurals d'agrupament humà autosuficient, encara que no sigui un llibre d'estricta actualitat en relació amb la feina agrícola. Els temps en què es planteja la conveniència del llibre d'Agustí són els de finals del XVI en què «es detecta una vertadera eclosió — en termes quantitatius- del contracte de masoveria» (Congost et al., 1999: 279). Entre aquest públic s'hi han de sumar els convents religiosos amb propietats rurals, amb jardins i horts. És simptomàtic que l'exemplar de la Maison rustique d'Estienne i Liébault, en l'edició de 1600, que tenim disponible a la Universitat de Barcelona, procedeixi del convent, desaparegut, de Sant Josep de Barcelona. Els masovers i els convents s'uneixen en un binomi que conforma una part important dels lectors interessats en el llibre d'Agustí a Catalunya.

No s'ha fet el seguiment de la repercussió dels Secrets en altres obres de temàtica agrària o rural, i sembla clar que un llibre amb tantes edicions ha de deixar rastre en obres posteriors de temàtica semblant; o no deixar-ne per alguna raó, tècnica o ideològica. Ací apunto només alguns casos (i és segur que n'hi ha d'haver molts d'altres):

a) No en sabem veure cap referència en el llibre de Francesc de Gilabert, Agri- 
cultura pràtica (1626), ni hi apareix en la llista d'autors que l'encapçala, encara que al final de la llista hi afegeix que no els esmenta tots («por no ser enfadoso dexo de nombrar-los»). Però en canvi sí que esmenta Herrera, l'autor castellà de més importància en el Renaixement, i que en Agustí no consta. El llibre de Gilabert té un objectiu molt clarament tècnic i ja no s'interessa per la tradició erudita, sinó per allò que en efecte s'ha de fer, i se separa del tot de la línia d'obres que volen transmetre el llegat agronòmic dels antics. Aquesta és una diferència fonamental, encara que és possible que hi hagi altres motivacions, potser ideològiques.

b) Contràriament, el Tractat d'agricultura d'un anònim pagès de Porrera, del segle XVIII, en fa referència anomenant-lo «agricultura de prior»; però, sovint, per mostrar-s'hi en desacord (Juncosa, 1998: 19).

c) En relació amb el molt copiat a Mallorca Art de conró de Montserrat Fontanet, escrit el 1747, Gaspar Munar interpreta que el llibre que s'hi esmenta com De secretis nature, et in variis libris de agricultura és una possible referència indirecta als Secrets d'agricultura d'Agustí per bé que també podria referir-se al llibre de Gabriel Alonso de Herrera o a altres llibres també en castellà (Ramis Puig-gros, 2001: 38-41). Però tot seguit fa un aclariment per dir que el seu objectiu no és recollir què diuen els altres, que considera que parlen de terres diferents de les de Mallorca, sinó del «poc que em consta per experiència». I en efecte redacta un manual pràctic amb referències a la realitat immediata, amb respostes a suposades preguntes que algú li pot fer, amb esment de poblacions mallorquines com Llucmajor, Campos, Santanyí, Manacor, Andratx, Marratxí, etc. Si hi ha deute amb Agustí es fa difícil d'escatir.

d) Marc Antoni Orellana (1731-1813), l'autor erudit de Valencia antigua y moderna, escriu en català el Catàlogo y descripció dels pardals de l'albufera de València, que és imprès a València el 1795, on, després d'esmentar diversos tractats clàssics de cacera d'aus, ens fa saber, en una molt breu referència, que coneix el «Pare Fray Miquel Agostí [sic] en la seua Agricultura, dita del Prior» (ps. 3-4), per bé que no es refereix a l'edició en català, que està organitzada en només tres llibres, ni tampoc en treu gaire res. Sembla aquí simplement una nota erudita.

e) L'alguerès Bartomeu Simon (1734-1817) resumeix en català alguns fragments dels Secrets (Armangué, 1996: 88). Segurament a partir de l'exemplar del llibre d'Agustí que es conserva a la biblioteca familiar Simon-Guillot (notícia que agraeixo a Andreu Bosch, especialista en el dialecte alguerès i el món agrícola de l'enclavament català a Sardenya). Armangué fa referència a uns resums dels «secrets» del pomer, del perer i del codonyer que tenen la funció de posar en relleu les tècniques dels empelts, que van tenir una enorme importància a Sardenya al s. XVIII en el que s'hi ha anomenat el «Risorgimiento de l'agricultura».

f) A la Cartilla rural en aforismes catalans, de Narcís Fages de Romà, publicades a Figueres el 1848, i que té versions en castellà i en francès, no apareix el nostre Miquel Agustí, malgrat que el Prior té alguns aforismes. En canvi l'autor explicita en la nota de la p. 82 una referència a Columel-la a partir de l'afo- 
risme «Símbol de pau l'oliver entre'ls arbres lo primer.» En nota diu: «Olea prima omnium arborum est» afegint-hi «lo mateix digué Abu-Zacaria y posteriorment Herrera, que són los tres escriptors més célebres de agricultura, tots espanyols per glòria de nostra Nació». Va als clàssics llatins i àrabs saltant-se els Secrets, en una època i un lloc i un personatge que se'ns fa difícil de creure que no coneixia el famós llibre del Prior.

g) Lo jardiner, hortolà y florista o modo ordenat de cultivar la terra segons ús y pràctica de bon pagès... segons la pràctica y costum dels PP Caputxins de Catalunya, obreta molt ben editada del 1852, impresa a Barcelona, recull continguts d'Agustí esmentant-lo com el «Prior» Així, per exemple, en relació amb la menta:

Prior. Se fa de arrels y de brots. No vol ser tocada de ferro, perquè la mata. (p. 19)

Fragment que, en efecte, correspon al d'Agustí: «Quant [la menta] és crescuda no convé tocar-la ab ferro, per què se moriria» (f. 31r), per bé que aquest «secret» ja apareix en les grans obres anteriors a Agustí i es remunta almenys fins a Plini. El tòpic apareix en Olivier de Serres (1600): «[Mente]. A en horreur l'attouchement du fer: par quoi n'en faut jamais cueillir les brins qu'à l'ongle, rejettant tous autres instruments» (Serres [1600], 2001: 878) i abans en Herrera en el Llibre 4, cap. XXXVII, que aquest sí confessa la font clàssica, cosa que no fa Agustí:

Y Plinio dice: que se daña si la tocan con hierro, y pro esso es mejor para ensalada o qualquier otro guisado desmenuzada con la mano que cortada con hierro, y no la corten ni sieguen con hierro ni la majen en almirez, que daña el sabor. (Herrera [1513], 1966: 321)

Fóra interessant de resseguir aquesta continuïtat del llibre del Prior en obres agronòmiques o relacionades amb el món agrari fins als nostres dies, cosa de la qual aquí no donem més que alguna notícia espigolada a l'atzar. Si més no, però, podem dir que Agustí ha deixat petja per tot el domini lingüístic català: a més del Principat i la Catalunya del Nord, que és on es gesta, deixa rastre al País Valencià, a les Balears i a l'Alguer. Segurament les darreres referències als Secrets d'Agustí són les del Calendari del pagès, que encara s'edita cada any, i on de tant en tant s'hi apunta una citació del Prior. No cal dir que el calendari té un fort regust de saber tradicional.

Per acabar només volem afegir que hem apuntat que Agustí és un nus important de la xarxa que formen els textos agronòmics europeus, tan imbricada en la història de la cultura, de la llengua i de la ciència des dels antics. Només dins d'aquesta xarxa, encara poc coneguda, podem entendre els Secrets d'agricultura de 1617; només afrontant la complexitat del context històric i cultural en el sentit més ampli posarem llum en els múltiples secrets que el llibre de Miquel Agustí encara té amagats. 


\section{Bibliografia}

Agustí, Miquel [1617]. Llibre dels secrets d'agricultura, casa rústica i pastoril. Dues edicions facsimilars: Barcelona: Altafulla, 1988, amb estudis preliminars de Lluís Argemí, Joaquim Garriga, Modest Prats i Albert Rossich i Amadeu-J. Soberanas; Vilafranca del Penedès: Andana, 2007, amb pròleg d'Emili Giralt i introducció de Xavier Luna-Batlle.

Argemí, L. (1985). «Agronomia y revolución agraria en España (1750-1820). A: E. Lluch \& Lluís Argemí, Agronomía y fisiocracia en España (1750-1820). Valencia: Institución Alfonso el Magnánimo, 1-43.

Argemí, L. (1988). «Presentació» a Miquel Agustí, Llibre dels secrets d'agricultura, casa rústica i pastori. Barcelona: Alta Fulla, 5-10.

Argemí, L. (2005). Història del pensament econòmic a Catalunya. Pagès Editor / Eumo.

Armangué i Herrero, J. (1996). Llengua i cultura a l'Alguer durant el segle XviII: Bartomeu Simon. Barcelona: Publicacions de l'Abadia de Montserrat.

BARANDA, C. (1989). «Ciencia y humanismo: la Obra de agricultura de Gabriel Alonso de Herrera (1513)», Criticón, 46, 95-108.

Bernat, P. (2008). Ciència, tècnica i agricultura a la Catalunya de la Il-lustració (17661821). Girona: Associació d'Història Rural de les Comarques Gironines.

Capuano, T.M. (2009). «Early Catalan Agricultural Writing and the Libre o regla o ensanyament de plantar o senbrar vinyes e arbres...». Al portal: Sciència-cat. La ciència en la cultura catalanes a l'Edat Mitjana i el Renaixement <http://www.sciencia.cat/biblioteca/documents/Palladi754_Capuano.pdf>

CAPUTXINS, PP. (1852). Lo jardiner, hortolà y florista o modo ordenat de cultivar la terra segons ús y pràctica de bon pagès... segons Liger y altres autors que se han ocupat en la matèria segons la pràctica y costum dels PP Caputxins de Catalunya. Barcelona: Impremta de Manuel Saurí.

Cató, M. Porci, (1927). D’agricolia. Trad. de Salvador Galmés. Barcelona: Fundació Bernat Metge.

Cazeneuve, X. (2008). «El manuscrit A-23 [=Cultura de jardins per governar perfetament las flors, arbres y plantas per la constel-lació de Barcelona]». A: Albert Garcia Espuche et al., Jardins, jardineria i botànica. Barcelona 1700. Barcelona: Museu d'Història de la Ciutat.

Cifuentes, L. (2001). La ciència en català a l'edat mitjana i el Renaixement. Barcelona: Universitat de Barcelona / Universitat de les Illes Balears.

Cifuentes, L. (2002). «Cavalls, bous i vaques: sobre manescalia i agronomia a Catalunya entre l'edat mitjana i la moderna». A: Actes de la VI trobada d'Història de la ciència $i$ de la tècnica, 87-91.

Colón, G. (1993). «"La gàbia gran no fa millor lo aucell”. Postil.la als Secrets del Prior Agustí». A: Miscel-lània Joan Fuster. Estudis de llengua i literatura. VI, 117-128. Recollit a: Estudis de filologia catalana i romànica. València / Barcelona: Institut Interuniversitari de Filologia Valenciana / Publicacions de l'Abadia de Montserrat, 1997.

Colón, G.; Soberanas, A.J. (1985). Panorama de la lexicografia catalana. Barcelona: Enciclopèdia Catalana.

Congost, R.; Gifre, P.; Saguer, E.; Torres, X. (1999). «L'evolució del contracte de masoveria (Girona, s. XV-XVIII)». A: Congost, R.; To, L. Homes, masos, història. La Catalunya del nord-est (segles XI-XX). Barcelona: Institut de Llengua i Cultura Catalanes de la Universitat de Girona / Publicacions de l'Abadia de Montserrat, 269-297.

DANTí, J. (2008). «Els cereals. Retrocés del guaret i conreus intesius». Història agrària dels Països Catalans, III: Edat Moderna, 91-124. 
DCVB = Antoni M. Alcover i Francesc de Borja Moll (1930-1962). Diccionari catalàvalencià-balear. 2a edició: 1975-1977.

DECat = Joan Coromines (1980-2001). Diccionari etimològic i complementari de la llengua catalana. Barcelona: Curial /La Caixa.

Fages de Climent, N. [1849]. Figueras: Gregori Matas de Bordallés. Facsímil editat per la Generalitat de Catalunya i la Diputació de Girona, 1985.

Fontanet, M. [1747] Art de conró. Pollença: El gall editor, 2001.

Fuguet, J. (2010). «Per una biografia de fra Miquel Agustí, prior del Temple de Perpinyà i autor del Llibre del Prior (1560-1630)». A: XVI Jornades de literatura excursionista, Homenatge a Pere Català Roca, Arxiu Bibliogràfic Excursionista de la Unió Excursionista de Catalunya de Barcelona, novembre de 2010, 285-299.

GARRIGA, J. (1988). «"La gàbia gran no fa millor l'aucell”: L'arquitectura rural postremença i el "siti i forma de la casa" segons Miquel Agustí». A: Miquel Agustí, Llibre dels secrets d'agricultura, casa rústica i pastori. Barcelona: Alta Fulla, 11-20.

Gilabert, F. (1626). Agricultura pràtica. Barcelona: Sebastià de Cormellas.

Giralt, E. (2002). «Les fonts del Llibre dels secrets de agricultura de fra Miquel Agustí (1617)». A: Mélanges offerts à Charles Leselbaum. París: Éditions Hispaniques, 327-339.

Giralt, E. (2008). «El conreu de la vinya». Història agrària dels Països Catalans, III: Edat moderna, Barcelona: 331-393.

GLICK, T.F. (1979). «Herrera y la obra De Agricultura». Introducció a l'edició de Gabriel Alonso de Herrera Obra de agricultura. València: Hispaniae Scientiae, 14-48.

Gras i Casanovas M. \& M.À. Pérez i Samper (1999). «Els tractats d'agricultura i l'alimentació pagesa a l'època moderna». Estudis d'història agrària, 13, 63-106.

Gulsoy, J. (1976). «El desenvolupament de les formes del subjuntiu present en català». A: Actes del Tercer Col-loqui Internacional de la Llengua i la Literatura Catalanes. Oxford: Dolphin Book, 27-59. També a Gulsoy, J. (1993). Estudis de gramàtica històrica, 377-415.

Herrera, Alonso de [1513]. Agricultura general, edición crítica de Eloy Terrón. Madrid: Ministerio de Agricultura, 3a. edición, 1996.

Juncosa, M.D.; Martínez, Catalina (1979). «Art de conró compost per Montserrat Fontanet... Mallorca, 1747», Estudis d'Història Agrària, 3, 165-196.

Juncosa, I. (1998). Tractat d'agricultura. Manuscrit anònim de Porrera, segle XVIII. Reus: Centre d'Estudis Comarcals Josep Iglésies.

Lieutaghi, P. (2001). «Introduction» a Olivier de Serres. Le Théâtre d'agriculture et mesnage des champs. Arles: Actes Sud, 7-54.

Llanas, M. (2002). L'edició a Catalunya, segles XV a XVII. Barcelona: Gremi d'Editors de Catalunya.

Luna-Batlle, X. (2004). «Variació històrica i dialectal dins Els secrets d'agricultura (1617) de Miquel Agustí, Estudis de llengua i literatura catalanes XLIX, Miscel-lània Joan Veny 5, 37-51.

Luna-Batlle, X. (2007). «Introducció» a Miquel Agustí. Llibre dels secrets d'agricultura. Vilafranca del Penedès: Edicions i Propostes Culturals Andana.

Luna-Batlle, X. (2011). Edició de Libre de plantar vinyes e arbres... Tractat d'agricultura del s. XV. Barcelona: Universitat de Barcelona / Ministerio de Ciencia e Innovación / Publicacions de l'Abadia de Montserrat.

Marcet, P. (1987). Història de la llengua catalana, I. Barcelona: Teide.

Martí EsCAyol, M.A. (2008). «Les fonts del Llibre dels secrets d'agricultura de Miquel Agustí. El MS754 de la Biblioteca de Catalunya i el MS291 de la Bibliothèque Nationale de France». Afers, 60, 289-311. 
Martí Escayol, M.A. (2012). Edició de De Re Rustica. Vilafranca del Penedès: Edicions i Propostes Culturals Andana.

Prats, M. \& Rossich, A. «El "Llibre dels secrets d'agricultura" i la prosa catalana a l'època del Barroc». A: Miquel Agustí, Llibre dels secrets d'agricultura, casa rústica $i$ pastori. Barcelona: Alta Fulla, 21-38.

Ramis Puig-gros, A. (2001). Estudi preliminar a Montserrat Fontanet, Art de conró (1747). Pollença: El gall editor.

Soberanas, A.-J. (1988). «Les edicions del "Prior"». A: Miquel Agustí, Llibre dels secrets d'agricultura, casa rústica i pastori. Barcelona: Alta Fulla, 39-45.

Solà, J. (1989). «El català a les gramàtiques i els diccionaris llatins dels segles XVIIXviII». A: A.M. Badia i Margarit i Michel Camprubí (eds.). Actes del Vuitè Col-loqui Internacional de Llengua i Literatura Catalanes (Tolosa de Llenguadoc), volum 2, $5-47$.

Terrón, E. (1996). «La experiencia derivada de la práctica agropecuaria, base de todo conocimiento», introducció a Alonso de Herrera. Agricultura general. Madrid: Ministerio de Agricultura, 3-37.

Torrent, A.M. (1989). «Llengua i poder polític a Catalunya al segle XviI. A: Actes del Vuitè Col-loqui Internacional de Llengua i Literatura Catalanes, II. Barcelona: Publicacions de l'Abadia de Montserrat, 29-55.

Torres, X. (2000). Els llibres de família de pagès. Memòries de pagès, memòries de mas (segles XVI-XVIII). Girona: CCCG / AHRCG / ILLCUG.

VENY, J. ([1974] 1978). «Sobre els castellanismes del rossellonès». A: Estudis de geolingüística catalana. Barcelona: Edicions 62.

VILAR, P. ([1962] 1979). Catalunya dins l'Espanya moderna, 1. Barcelona: Curial / Edicions 62. 